\title{
1. Universities in Europe and local engagement
}

\subsection{RESEARCH UNIVERSITIES IN EUROPE}

Currently, the European higher education landscape is characterised by a diversity of organisations devoted to teaching and training. ${ }^{1}$ Each has its own niche and contributes to society in different ways. Many are relatively small-sized, while some universities ${ }^{2}$ have tens of thousands of students and staff. The primary mission of universities is to offer a stable environment for the education of learners and students; their main product is to deliver well-trained and skilled graduates. Through their teaching and training activities these organisations may act as engines for social mobility, contribute to social and cultural development, and provide inputs for citizenship development and the human resources for knowledge-based economies. Delivering highly qualified workers as well as high-quality knowledge for general usage, most universities have been key contributors to municipal, regional ${ }^{3}$ or national societies.

The European Union Member States collectively hosted 2593 Higher Education Institutions (HEIs) in 2016, including 1009 universities. Almost

1 A Higher Education Institution is an organisation providing higher, postsecondary, tertiary, and/or third-level education (levels 5-8 of the International Standard Classification of Education structure). The main organisational mission of universities is teaching and training of students.

2 A 'university' is a doctorate granting HEI with an official research mandate, and/ or inclusion of scientific research in its strategic objectives and plans, that have one or more institutionally recognised research units, and at least one regular $\mathrm{PhD}$ programme. Some universities have distributed campuses, across various locations. Other universities run one or more branches in other regions or countries.

3 In this book we will denote a 'region' as a within-country area; either an administrative entity or a spatial territory. In practice, universities may apply the term without any pre-defined or clear geographical demarcation, or perceive their region more broadly, where the designated area extends into a neighbouring country. With regards to the 'distributed universities', those with several campuses or branches (in the same region, country or elsewhere), our discussion of the 'region' and RII analysis will only focus on the area or territory surrounding the university's main campus or home city. 
every NUTS2 ${ }^{4}$ region in the EU28 ${ }^{5}$ had at least one HEI within its territory, while 59\% of the NUTS3 level sub-regions hosted an HEI (ETER, 2019). In this book we focus our attention on one specific type of HEI: research active universities. ${ }^{6}$ There is no generally accepted definition of such universities and hence no official statistic on their numbers within the EU. If we apply a conservative estimate by selecting all HEIs indexed by the U-Multirank database (www.umultirank.org; 2020 edition) that produced at least 50 international research publications in a recent four-year period, we count 725 HEIs in the EU28 and 590 in the EU27 (excluding the United Kingdom). As public sector organisations, these universities have two main institutional missions: education and scientific research. Research universities are a hotspot of learning and skill development, but also a reservoir of creativity, knowledge and know-how. Universities have an essential role in developing human talent. They are, by their very nature, well suited to provide creative and innovative solutions to address complex societal problems and challenges; the combination of knowledge domains allows them to contribute from different perspectives where students can experience hands-on projects in problem-based, interdisciplinary contexts.

Scientific research gradually entered the mission portfolio of universities in the 19th century, an era in which the United Kingdom founded many 'civic' universities, often with financial support from business and the local community, to underpin the development of its industrialising cities (Goddard and Vallance, 2013), while the US Land Grant universities had a similar role (Rosenberg and Nelson, 1994). Germany saw the establishment of the Humboldtian universities (Östling, 2020), although their specific regional role was less pronounced. The societal and economic impact of research universities have greatly expanded ever since. The European higher education sector boomed in the second half of the 20th century, driven by a massification of student numbers and rising budgets from governments for science. Nowadays, many universities are heavily involved in scientific research; they tend to conduct a significant amount of 'basic' discovery-oriented scientific

4 The NUTS classification (Nomenclature of territorial units for statistics) is a hierarchical system for dividing up the economic territory of the EU for the purpose of collecting, developing, and harmonising of statistics at regional level.

5 The EU28 refers to the current 27 Member States of the European Union and the United Kingdom, which withdrew on 31 January 2020. We use this term when referring to data before this date which includes the United Kingdom.

6 Throughout the book we will intermittently use the term 'research active university', 'research intensive university', 'research university' or simply 'university' to denote the multi-mission universities that provide education, conduct scientific research, and are engaged in 'other services'. 
research but also 'application oriented' research, with support to related socio-economic and technological development. Large-sized research universities in Europe are expected to conduct 'excellent' scientific research with a noticeable scholarly impact.

Academic research is no longer only about creating stocks and flows of scholarly knowledge; the transfer of technical expertise, advanced skills or opening up university infrastructures for economic utilisation has become a vital 'third mission' of many universities. ${ }^{7}$ Playing a key role in many national or regional innovation systems, research-active universities create and disseminate knowledge and skills for the benefit of their students, staff and external users. Such engagement is increasingly seen as one of the three main functions of the higher education sector, reflecting the responsibility of universities to provide social, economic or cultural benefits to wider society. Effective engagement is an interactive, bi-directional process that renders universities more responsive to societal needs and enhances the relevance and impact of higher education and research activities.

Towards the turn of the century 'civic engagement' and 'community service' gradually emerged as topics of strategic interest within university management (e.g. Bok, 1982; Kerr, 2001). Universities now offer a range of professional services beyond teaching, training or knowledge production. As 'multi-mission' organisations - that are governed to create a sustainable and responsive environment for productive interactions between students, staff, civic society and the business sector they have become intertwined with their host societies and local economies. The university's third mission and its social purpose has become ever more prominent during this millennium. A fair share of the universities with an extensive volume of third mission activities - often universities of technology - played a key role in promoting entrepreneurship and job creation, marked by the rise of the 'entrepreneurial university' in the 1990s (Clark, 1998). Its economic impact is often seen as intricately linked to the ability for fostering 'knowledge intensive entrepreneurship' (Malerba et al., 2015).

The expanding portfolio of organisational missions has brought their wider civic engagement mission to the fore during the last decade, ${ }^{8}$ especially their ability to develop and apply new ideas, services and products of

7 Molas-Gallart and Castro-Martínez (2007, p. 321) define the 'third mission' as: "All activities concerned with the generation, use, application and exploitation of knowledge and other university capabilities outside academic environments."

8 The rise of the civic engagement mission of universities in Europe is driven by various factors. It is partly a response to growing inequalities in terms of socio-economic opportunities within cities or regions, but also a reflection of changing policies in higher education (see e.g. Benneworth and Osborne, 2014). 
socio-economic relevance - what we now usually describe as 'innovation' (Uyarra, 2010; Uyarra and Flanagan, 2010). Increasingly, universities are also considered to be places that launch their own knowledge-based innovations and/or contribute to the development of innovative, marketable products that are produced elsewhere. The partners or customers of such 'entrepreneurial' or 'innovative' universities may involve business enterprises, government agencies, civic society organisations, regional development agencies, or individual citizens. Universities may, for example, collaborate with private firms to help co-develop a more competitive business sector, or close gaps between academic research and business-sector technological innovation. However, these market-driven innovations are just one component.

Although less visible from an economic viewpoint, many universities are also involved in community engagement, which has increasingly become a major part of a university's 'soul' (Brink, 2018). It may include student volunteer projects, service-learning, community-based participatory research, community access to sports facilities, or the co-organisation of cultural events. The outcomes are diverse and may include 'social innovations': new ideas, initiatives and developments in areas such as education, cultural development, environmental protection, or social awareness. Impacts of such innovations can be far-reaching, although a university's civic engagement is often focused on the local area - either in their home town or the wider metropolitan area.

\subsection{UNIVERSITIES AND REGIONAL DEVELOPMENT}

The socio-economic contributions of universities to their home town, local region or country have long been thought to be considerable (Cooke, 1970). Studies by Caniëls and Van den Bosch (2011), and more recently by Kempton (2019), provide general overviews of factors that determine the role of universities as contributors to regional innovation and regional development. The university's organisational size, and the geography of higher education, are two such factors. Some universities are firmly rooted in their local cities or metropolitan areas; their outreach and level of engagement, along with strategic plans and long-term vision statements testify to this embeddedness and their degree of commitment. Their relative regional footprint is the reflection of community orientation and local circumstances.

Whereas smaller universities in rural areas are more likely to mirror the societal fabric and economic specialisation of their local area and regional hinterland, large universities located in urban areas or metropolitan hubs tend to be more diversified in their teaching programmes and research portfolios. Rural universities may provide (inter)national gateways for their regional communities, while urban universities can collaborate with city authorities to implement 
development strategies and urban revitalisation. Large research-intensive universities are more likely to be 'spatially blind' in terms of pursuing a teaching or research agenda without an explicit municipal, metropolitan or regional focus. Some of those universities may nonetheless have regional innovation at the heart of their activities, but do not necessarily perceive themselves as a 'regional university'. However, in general they are more likely to downplay their local relevance and are less concerned with challenges, tensions and problems regarding their regional engagement. Their regional orientation is often implicit rather than explicit, and their regional engagement may not be a separate strategic dimension but integrated in educational and research activities. In such cases, their identity and aspirations are likely to be driven by broader organisational missions or long-term visions on the university's goals, achievements and impacts in the world, or by a more implicit focus on community engagement, in terms of, for instance, organisational goals related to sustainable development, inclusion and social commitment.

No large-scale systematic study has ever been undertaken to assess why some universities are much less inclined, or much more, than others to engage locally or regionally. We simply lack the appropriate information sources to conduct such large-scale systematic studies based on comparative empirical evidence. Accelerated by impacts of the current COVID-19 pandemic, many universities are undergoing deep organisational transformations. Challenged by a variety of social and economic forces, universities in general, like many other traditional institutions in society, find it difficult to embrace radical change in their internal structures. Organisational inertia, financial barriers, work culture obstacles, managerial practices, or human resource constraints may hold them back. The vast literature in the field of higher education studies offers a wide range of change-limiting factors, both organisational ('internal') and environmental ('external'), that help explain the relative neglect of local community services or other regional engagement activities. With regards to the organisational side, many universities have been affected by mission expansion and diversification during the last 20 to 30 years. On top of their traditional educational and research missions, large and comprehensive universities have faced a seemingly never-expanding stream of tasks, requests and demands from government funders and other major stakeholders. ${ }^{9}$ Nowadays,

9 The following non-exhaustive list is illustrative of how large and diverse the task load may become: offer access to learners and students; provide living and transport facilities to students; provide teaching and training inspired by research and science; employ new and more effective teaching techniques; deliver sufficient numbers of skilled workers and human talent; ensure employability of its students; produce advanced knowledge for problem solving; conduct excellent scientific research; demonstrate quality, societal relevance and social responsibility; act as an engine for 
universities are also increasingly subjected to government pressures and political desire to contribute more to local or national economic development (e.g. Mejlgaard and Ryan, 2017). Managing such a gradually expanding portfolio leaves little room for further development or prioritisation of regional engagement. Municipal or regional engagement can bring benefits, but also distractions from other tasks and missions. Not surprisingly, when pursuing such diversified ambitions, the local city or region's regional mission may be perceived as of lesser importance on a university's list of strategic priorities.

Management systems and organisational culture are another cluster of institutional factors that may hamper regional engagement. Universities are professional work organisations that are only very generally steered by executives with regards to their outreach in the host city or immediate surroundings. The university's organisational culture - a product of its core values, norms or beliefs - is an important determinant of the value it can add, but it is also driven by domestic or global factors such as high-profile collaborations, measures of excellence or funding structures. Funding is largely shaped by national policies and tends to be determined by the volume of student enrolments or number of graduates. Universities may therefore lack sufficient organisational autonomy to develop added value with a regional development dimension. External pressures to engage in regional activities may also conflict with a university's strategic plans.

Governance structures also matter. The role of university leadership is often fundamental in shaping effective engagement relationships with regional actors, which is shown by the examples of Aalborg University (see also Appendix C) and Aalto University (see also Rissola et al., 2017). Without such leadership nothing or very little will happen regardless of other factors. Regional development policies and initiatives may not survive the test of leadership changes. And a lack of a common view between university leadership and representatives of regional bodies in the university's board of trustees may hamper the development of strategies for more effective regional engagement. However, university leadership and executives may have limited capacity or managerial tools for steering their staff behaviour, especially in large research-active universities with global ambitions. At such universities, many of which can be typified as 'loosely coupled' organisations (Benneworth et

social mobility; contribute to citizenship development; participate in societal debate; address global challenges like climate change and poverty reduction; create infrastructures and socio-economic environments that allow technological innovation and (social) entrepreneurship; provide inputs to technological innovation; engage in technology transfer and cooperate with the business sector; earn an income from the marketplace; contribute to municipal, regional or national competitiveness; produce new ideas and insights with significant societal or cultural impacts in local communities. 
al., 2017a), decision-making is often decentralised to faculties or departments. Even though the executive level at universities may have adopted a positive stance on engagement with other actors in the local city or region - usually expressed in a high-level strategic plan or a general mission statement - that sense of commitment may be less present at the level of departments or other organisational units that lack dedicated resources, managerial strategies or organisational efficiencies to interact and cooperate with regional public authorities, local businesses or other potential partners. Radical changes in longer term visions are then likely to meet resistance within the organisation.

Regional engagement is usually not considered a key criterion for promotion of university professors, nor are there prestigious prizes to be won by academics for such 'third mission' activities (Stanton, 2008; Benneworth, 2012). As a result, such engagement is too often dependent on the drive and motivation of a few individuals, rather than pursued as an organisation-wide ambition (Kempton, 2016). Most incentive structures or academic recognition systems are shaped by national funding systems and regulatory regimes that have little effect on promoting or stimulating a local or regional orientation by universities (Charles et al., 2014). The agendas, priorities and careers of academics engaged in research activities are much more likely to be determined by a striving for (inter)national 'scientific excellence'. The 2014 edition of the Research Excellence Framework in the United Kingdom introduced non-academic impact as a component to measuring research excellence. The results showed that just over a third of the 6795 impact case studies submitted by UK universities described social or economic impacts; most of those tended to be international impacts rather than domestic or regional ones (Kempton, 2019).

Globalisation has become an increasingly important determinant in university strategic management. During the last two or three decades many universities embraced the tempting opportunities offered by internationalisation and digitalisation. Driven by economic considerations, universities have prioritised their international prestige and global outlook to enhance their attractiveness for lucrative foreign students or industrial partners. Universities with an explicitly regional focus might actually be regarded as 'second tier' by those national policymakers whose main concern is national achievement or international measures of success (Hazelkorn, 2016). Localisation and regionalisation seem to have taken a back seat to globalisation processes - especially in the case of research active universities in countries with a strong position in the global higher education arena such as the United Kingdom (Tijssen et al., 2020). Nonetheless, a university's regional engagement can be mutually com- 
patible with its global outlook, especially in the current era where most 'grand challenges' that societies are facing have both global and local ramifications. ${ }^{10}$

Counteracting these dominant structural patterns in favour of more regional engagement is difficult, but not impossible - most universities tend to adapt quickly to any major financial opportunity that presents itself with regard to their third mission. Nonetheless, short-term funding opportunities and other incentives - at either the organisational, municipal or regional level - are usually dwarfed by the available longer-term resources and high-reward initiatives made available at the national or supranational level. The university's regional impacts and its related third mission's achievements are likely to be less recognised and severely undervalued. ${ }^{11}$ Unfortunately, 'regional impact' is largely ignored in most world university ranking systems and their lists of performance indicators (Hazelkorn, 2018). ${ }^{12}$ Although some ranking systems incorporate employer surveys, providing a general idea of student employability, none of the current rankings explicitly take into account their capacity to respond to the need for skills adapted to the local labour market nor the regional innovation achievements of universities. Clearly, such ranking systems penalise smaller universities or those that are primarily engaged in tertiary vocational education and training. Not surprisingly, many universities are looking towards other ways, such as HEInnovate,,$^{13}$ to develop or monitor their innovation potential and entrepreneurial capacities.

Even if dedicated policies and incentive systems exist within universities to promote or support local engagement, the university's organisational history or cultural heritage may prove a supply-side impediment for achieving high levels of commitment and engagement. Supply/demand mismatches are almost inevitable given the complex dynamics of modern societies and interconnected economies. Lack of opportunities for collaboration with civic society partners

10 Whereas UNESCO's Societal Development Goals (SDGs) is probably the best known example of grand challenges with a focus on low- and middle-income countries worldwide, Europe's grand challenges are more related to energy transition, health (ageing, obesity), urban quality of life, and sustainable economic development and competitive advantages (e.g. European Commission, 2019a).

11 The core concept 'impact' (or alternatively, 'influence') is too complex to pin down in any satisfactorily comprehensive way owing to its non-linear, emergent, and diffuse nature. This book will nonetheless operationalise impact in the context of identifiable or measurable consequences of university action (be it intentional or unintentional) on their municipal or regional innovation system.

12 The available information on regional impacts and engagement may increase in the future as a result of ongoing technical developments within some world university systems such as U-Multirank.

13 HEInnovate, an online self-assessment platform, is further introduced in subsection 3.2. 
within the local region, or fledging knowledge-absorptive capacity of business enterprises, may have mitigating effects on the demand side. The university's educational offerings or its research profile may not align with the needs of the municipal or regional economy (Birch and Cumbers, 2010). Their home town might suffer from its industrial structure having insufficient absorptive capacity or the local region may be comprised of loosely coupled rural communities. In the extreme case, large research-intensive universities may be perceived as 'cathedrals in the desert' (Morgan, 1997), sources of knowledge that are located in 'peripheral' regions with hardly any knowledge-based industry and low levels of absorptive capacity. At the other extreme, we may find specialised private colleges operating in a dynamic and diversified metropolitan area with a very competitive local higher education environment, in other words 'service providers in the big city'.

In both cases, it is important to note that such varied environments do not necessarily determine the actual 'functional spaces' in which universities are most likely to create significant socio-economic impacts and benefits. The university may operate within a regional environment constrained by national regulations or municipal bureaucratic obstacles. Universities are characterised by their own unique impact profiles, that may reach far beyond what is considered their locality or region. Funders tend to treat universities as relatively homogeneous organisations and fail to recognise significant levels of diversity (Uyarra and Flanagan, 2010), where differences are amplified by the local or regional policy environments and socio-economic circumstances in which they operate (Edwards et al., 2017).

Not surprisingly, universities often feature prominently as core components of regional innovation policies (Huggins and Johnston, 2009a), with a special emphasis on their developmental potential in peripheral regions (Huggins and Johnston, 2009b; Huggins and Kitagawa, 2012; Brown, 2016). Despite the many obstacles and disincentives mentioned above, most universities in Europe aim to meet - to varying degrees, in multiple ways and under different conditions - the diverse societal and economic needs and wants in their surrounding region. Universities may play a pivotal role in their region, both as knowledge producers and as an interface between public and private sector partners. Strategic regional engagement with a range of municipal and regional partners may create incentives and infrastructures within universities to manage and steer such processes and contribute to public-private networks (Chatterton and Goddard, 2000). The notion of 'regional innovation systems' (Cooke et al., 1997; 2004; 2011) puts universities at the heart of regional knowledge economies and innovation-driven networks. Many universities have always been core actors in regional innovation systems and contribute to economic development, especially in high-income regions and countries (Goldstein and Drucker, 2006; Drucker and Goldstein, 2007). 
RII success stories are highly dependent on the local supply of knowledge and resources. In some cases, universities act as powerhouses for urban and rural development, where universities partner extensively with local and regional authorities, and closely linked knowledge-intensive firms in the business sector. Such levels of regional engagement tend to create positive agglomeration effects in terms of connections and collaborative networks within regional knowledge infrastructures. In other cases, universities may simply lack the sense of urgency, critical resources or necessary infrastructures to develop or exploit relationships with external partners for the purpose of regional development. Opening up and collaborating with external partners can bring an innovation dividend to their local regions, where universities can act as a pipeline or as a node in a local network, allowing actors in the region to access global knowledge resources. Such knowledge spill-over or network effects may extend far beyond the host town or region. Usually it is not universities as strategic bodies that engage with the region but academics who are pursuing their own agenda and goals. These individuals and their teams engage through many different kinds of activities and relationships that are not always clearly visible and almost impossible to measure or count. But the fact that individual initiatives are often 'under the radar' does not mean that they should be downplayed or ignored. Both 'soft' social innovation activities and 'hard' technological innovation actions are important. But the soft side tends to be undervalued; while their contributions are comparatively small and diverse, all those commitments, linkages and activities may add up to a substantial regional impact.

Getting universities to contribute to regional innovation processes can be problematic. Universities do not always have the right kind of incentive structures to become more heavily engaged with regional partners, partially because they are not meant to act as regional development agencies and also because of organisational practices which are, by nature, difficult to change and often resistant to external pressure. So, how to encourage universities to improve their level of engagement, to become more participative and responsive? Universities would need to strengthen their societal position, beyond the traditionally accepted organisational parameters, to enhance their regional impact. The European policy challenge lies in developing effective initiatives, incentives, and interventions - focusing on higher education, science, technology and innovation - that may help improve knowledge spill-overs from universities (e.g. Laranja et al., 2008).

However, the range of options and opportunities for engagement differs between universities and their home regions. Universities in many European countries enjoy a considerable amount of organisational autonomy, a result of historical developments stretching back to earlier centuries, or more recent national governance arrangements. This situation severely limits the options 
for regional, national and European policymaking actors to directly steer the behaviour of universities. Nonetheless, universities in Europe are heavily dependent on funding from external sources - either institutional funding, project funding from public sources, or income streams from private and public sources in the form of contract research. In many countries additional income is generated through student fees and as compensation for services offered to external parties. This dependence on external funding can offer policy actors the potential to influence university behaviour.

There are three main kinds of territories or situations that are likely to suffer from suboptimal levels of regional engagement: fragmented cities, old industrial regions, and remote rural areas. Although some universities are actively involved in urban or rural regeneration projects (Addie et al., 2018), the general tendency among many universities to disregard the local socio-economic environment has become a policy problem of some urgency, especially among European Commission policymakers. Policy reports state that universities could and should open up and contribute more to their own city and region than they are currently doing. In their assessment of universities in Europe, the Pascal Lamy-chaired 'Independent High-Level Group on maximising the impact of EU Research and Innovation Programmes' argues for a programme of institutional 'modernisation' for universities to accelerate that process (Lamy et al., 2017).

Supporting universities to evolve further in this direction may require new instruments at the European, national or regional level. Over the past two decades, governments across Europe have implemented performance-based funding systems for the allocation of institutional funding to universities according to ex post assessments ${ }^{14}$ of their research performance (Jonkers and Zacharewicz, 2017). Some of these funding systems assess and incentivise universities based on other, broader missions including their societal impact. Both the Lamy report and the RISE report (European Commission, 2019b) also mention the possibility of top-up institutional funding streams for universities in EU Member States, on the basis of their 'innovation performance', to enhance the positive effect these organisations can have on regional innova-

14 For the sake of simplicity and clarity, we will use the catch-all word 'assess' (or 'assessment') throughout this book, rather than to differentiate between ex ante 'assessment' and ex post 'evaluation'. This distinction could lead to confusion in cases where the formal status of the review, or its (ultimate) operational objective, are ambiguous or not specified. The term 'monitoring' is applied to systematic processes aimed at observing progress and/or measuring temporal changes of an entity over a sustained period of time. 
tion systems. The RISE report, produced by an independent group of policy experts, contracted by the European Commission, argues:

At the regional level, HEIs can mitigate this shortcoming by being catalysts in the creation of regional, inter-regional and global quadruple helix clusters that can be mobilised to enhance their region's social and economic impact through the global exchange and sharing of research and innovation knowledge, learning and experience (pp. 49-50) ${ }^{15}$

and recommends the introduction of an additional funding stream:

... giving extra funding, not simply as a prize but perhaps in some kind of longer-term funding, to universities that meet different innovation targets, or better still (in terms of changing incentive systems) to universities whose professors on average meet certain innovation targets, such as spinoff companies, curricular innovations, local employment growth, representation on company boards, participation in product development teams or other engagement measures. (p. 83)

Such performance-based funding resonates with the above-mentioned 'modernisation' agenda, but issues of operationalisation would need to be placed within an appropriate framework that stimulates universities to develop or transform their regional engagement portfolios in the desired direction. The wider innovation-oriented agenda within the EU, and reflections on ways to promote the contribution of universities to regional economic development has spurred studies within the European Commission to develop a model and framework that can assess contributions and positive impacts of universities to their regional innovation systems (Jonkers et al., 2018).

The design of corresponding incentive systems and funding mechanisms may strongly influence the way universities position themselves as actors within local or regional innovation systems, as they provide both incentives for individual students and staff, as well as the organisation as a whole. Any progress on this issue requires a cautionary approach where expectations are set at an appropriate and realistic level. If we assume the policy problem might be solved by government policy interventions or funding instruments, which strategic issues and challenges should then be addressed within the context of evolving and often controversial policy goals across Europe? How to encourage universities to re-value and enhance their regional innovation footprint, given that most of the current incentive systems steer universities away from higher levels of regional engagement and more cooperation with regional partners? These questions are addressed in Part III of this book.

3.1 .

For more information on the 'quadruple helix', see the first paragraph of section 
Clearly, any proper appreciation of regional missions and local aims requires a better understanding of the broad range of interconnected factors by which their regional engagement is initiated, driven and determined (Benneworth et al., 2017b). Such an understanding starts with creating as much clarity as possible with regards to the complex nature of the problem, where results of this diagnosis are then used to develop practical solutions. If there is one clear message from the history of European policy cooperation over the last 40 years, dating back to the 1980s CERI report 'The University and the Community' (Centre for Educational Research and Innovation, 1982), ${ }^{16}$ it is that universities' regional engagement and contributions to innovation systems are complex and difficult to address.

Analytically, we are dealing with a 'wicked problem' (Churchman, 1967), one that can never be satisfactorily solved, because of adaptive social systems. The highly dynamic nature of underlying processes renders it difficult to systematically identify and monitor the nature and intensity of university contributions. First, one needs to identify the opportunities, challenges and tensions that universities may face in those missions, to be analysed with an appropriate contextualised model, a versatile analytical framework and robust empirical data. Second, any approach is only one of a wide variety of possibilities, each introducing a particular perspective of how universities (might) engage with their local and regional environment. Irrespective of the analytical lens, a thorough understanding of key concepts, in our case 'regional innovation impact', is the bedrock of any sound approach.

\subsection{WHAT IS 'REGIONAL INNOVATION IMPACT'?}

Introduced as a new abstract concept a few years ago (Jonkers et al., 2018), the construct 'regional innovation impact' (RII) derives its meaning from the alignment of three attributes: 'region', 'innovation' and 'impact'. Basically, RII refers to an immediate effect or longer-term influence (the 'impact') of an innovation that occurs (or has occurred) within a particular local geographical area. RII is a slippery concept. It is multi-dimensional, interactive, time-dependent, and context-specific. If we want to link RII to universities and their impacts, we need to be more specific. In this book, we define RII as:

an immediate or longer-term impact of an innovative outcome, within a local geographical area, which is directly linked to resources, processes or outputs that

16 The CERI report studied the tendencies of universities to interact and cooperate with nearby communities. The report presented the best practices of university engagement, including North East London Polytechnic Company and Catholic University of Leuven in Belgium. 
involve active participation of individuals and/or sub-units within a higher education institution located in that same area.

In this context it is important to stress that RII is not synonymous with a university's 'third mission', the latter being a much broader domain of activity. It distinguishes between innovation outcomes that benefit the economy and society at whatever geographical level, with those that have a clear impact within the locality (Goddard and Vallance, 2013). The geographical factor is essential in defining and identifying RII. For example, innovation projects with firms outside the region are part of a university's external 'third mission' engagement, but do not necessarily have a local economic impact. Conversely, the geography of such impacts can be blurred because RII may have 'spill-over' effects and benefits outside the region (see section 1.2).

As for 'innovative outcome' and its underpinning generic concept 'innovation', we will also need to be more specific. Since there are so many definitions and descriptions of 'innovation' in the management literature and business practice, we settle for a simple, summarised version of a more sophisticated international definition that is used by many (supra)national statistical offices in innovation surveys specifically targeted at business enterprises and data-gathering on economic development (OECD/Eurostat, 2018): An Innovation is "a novel or significantly improved product, process or service". ${ }^{17}$

Adopting the OECD/Eurostat framework and applying this relatively simple definition, the 'innovation' always materialises in an external user environment. The novel or improved 'product, process or service' can only be perceived and acknowledged as an innovation by external customers, consumers, partners or other 'third party' users - either individuals or organisations within civic society or the business sector. Innovation impacts can therefore only occur outside the university. Moreover, adopting this particular definition of innovation, most universities are likely to be 'RII active', albeit in different degrees and ways. First and foremost, through their graduates getting employed, either in local public organisations and business enterprises, who will deploy the graduates' knowledge and skills to introduce innovations in their workplace. In this sense, a university's regional impact cannot be limited to its 'third mission' activities, since it is integrated with its other mainstream activities, namely education and research.

17 The full version of this definition, as mentioned in the Oslo Manual 2018, is: “An innovation is a new or improved product or process (or combination thereof) that differs significantly from the unit's previous products or processes and that has been made available to potential users (product) or brought into use by the unit (process)" (OECD/ Eurostat, 2018, p. 60). 
Trying to pin down RII obviously invites different perspectives on what the innovation actually is, or the nature of the innovation impact. Notably between 'producers' and 'users': regional authorities may have a radically different view of RII from that of universities, where disagreements may occur over if, when and how an alleged 'effect or influence' actually happened. Discernible impacts may range from short-term minor contributions, generated by small-scale individual projects of individual students or staff, to major longer-term benefits from large-scale infrastructure programmes or core missions of universities. RII may, for instance, include newly minted graduates moving into jobs where they can apply their knowledge and skills to improve management practices, but also $\mathrm{PhD}$ students starting up companies to co-develop IT solutions in collaboration with local community workers, or university professors advising regional government authorities on how to deal with environmental problems. They can also include high-profile, public-private initiatives such as new science parks or innovation hubs co-developed and co-managed by universities, local governments and business sector partners. It is within such 'place/space' environments that universities can go about creating RIIs to develop or support knowledge-based regional innovation systems.

Some European policy advisors (see the above-mentioned reports by the Lamy and RISE expert committees) argue that the innovation impacts of universities are less than what one would expect to see, or what is badly needed in the current economic circumstances. This would mean that universities are not fulfilling their RII potential. True or false? The policy perspective matters to address this question. Adopting a broad definition of 'innovation' as we do in this book (see above OECD/Eurostat definition), it is clear that universities can contribute to such innovations in many ways. European innovation policies tend to focus on 'technological innovation', where academic scientific research or university-developed prototype technologies may provide essential inputs to innovation processes. However, an overemphasis on the role of science and technological development in innovation may gloss over the most valuable output of universities for society and the economy: their smart and creative graduates, who can lead and catalyse the long-term provision of new knowledge and ideas and are technologically savvy and innovative. The skill set and competences of graduates are of major importance to regional innovation systems in Europe (e.g. Hazelkorn and Edwards, 2019).

Moreover, universities may argue that their 'regional', 'domestic' or 'global' missions are intertwined; their regional engagement simply cannot be isolated from their other activities, goals, and ambitions. They may also argue that their organisational decision-making on how to distribute their scarce resources across these geographical domains is inevitably a trade-off between short-term economic constraints or strategic priorities rather than a matter of 
longer-term, community-driven sense of civic responsibility. The degree to which universities are fulfilling their RII potential will remain unclear without detailed information on their RII potential, or clues as to the extent and nature of their RII capabilities.

RII can materialise in many ways and across varied timescales. Furthermore, RIIs are rarely isolated one-off events that can be easily traced back to a single source linked to a specific university. More likely, RII comprises a 'dynamic system' of chance events and randomness, of partial causality and loosely connected contributions. Not only is determining the causal attribution a challenging analytical undertaking, assigning any reliable valuation (monetary or otherwise) to such an impact is equally problematic. RII analytics and assessment will require a sophisticated 'smart' approach that takes these issues into account.

\subsection{MODELLING A UNIVERSITY'S RII SYSTEM}

Not surprisingly, meaningful and workable operationalisations of RII are still very much 'work in progress', whether describing their role in a university's engagement mission or gauging impacts of that same university in the local business sector. In 2018 we launched the notion of RII and introduced the first version of a conceptual and analytical mode (Jonkers et al., 2018). Further development requires more robust models, but above all an information and analytical architecture that can deliver relevant facts and evidence. Any convincing, high-quality RII analytical framework requires access to reliable empirical information, generally accepted measures of RII performance, user-friendly diagnostic tools, and ideally, automated 'track, trace and isolate' detection algorithms.

To get a grip on all these requirements, let us start with the foundation: empirical information on RII activities and outcomes. RII-relevant case studies have recently started to emerge, bringing specific or contextualised insights. A study by the European University Association (EUA) entitled 'The Role of Universities in Regional Innovation Systems' presents case studies of nine universities in Europe each with empirical evidence of how these universities are integrated in the innovation system of their local city or region (Reichert, 2019). Adopting a university management perspective, the underlying analytical model of that study focuses on the role and contributions in six areas: culture of the system; human capital supply; knowledge production; other support structures (funding, services and infrastructures); organisational and regional strategies; processes; network communication channels and formats. The results provide interesting insights and methodological guidance on how relevant empirical information can be extracted from universities, their local partners and regional stakeholders. But it presents only one small sample of 
universities and it applies one specific analytical lens. There are many more universities across Europe, and numerous other ways of studying RII and conducting an 'analysis' or an 'assessment' of RII achievements. ${ }^{18}$

A large degree of divergence is to be expected among the thousands of public and private universities in Europe. The legislative, political, geographical, and socio-economic circumstances in which universities in Europe operate may diverge in several significant dimensions. The European higher education space comprises a heterogeneous collection of national systems that can be crudely classified into 'unitary systems', which are dominated by universities, and 'dual systems', where higher education institutions outside the university sector account for a very significant share of students (ETER, 2019). Operating within such systems, universities themselves are multi-input, multi-output organisations which may differ enormously in size, nature, and mission. Each university is the product of distinct historical, social, economic, and intellectual development processes and therefore defines its own organisational profile of teaching, research, or a broad range of other activities.

Although our above definition of RII is by no means comprehensive, it does contain several relevant features that enable us to explore the feasibility of a 'RII framework' which may help reduce the staggering complexity described above. The backbone of this framework should comprise an overarching 'Theory of Change' model (see section 3.2) as well as an associated analytical model that is specifically designed to collect and process RII relevant information. It should be a generally acceptable model that captures key features of observable realities and their dynamics. This means that elements of the RII definition need to be operationalised in a way that is recognisable and analytically feasible for universities. To begin with, let us focus on two core components of the RII definition: '... processes and outputs ...'. This is a hotchpotch of facilities, activities and (intermediate) results - including all their interconnections and interdependencies.

Figure 1.1 presents a circular model with two main spheres (the university and its external environment), where universities influence actors in their local or regional environment and vice versa through a web of interconnected elements, flows, and feedback loops. Local or regional authorities are one of the key actors in that environment, who may articulate the RII-related socio-economic problems, command their own RII-relevant resources, and

18 The distinction between 'analysis' and 'assessment' is important in this book: Chapters 1 to 8 are mainly concerned with analysis and analytical frameworks, whereas Chapters 9 to 11 turn to the use of the framework for assessment. By 'analysis' we mean a detailed description, monitoring or examination of RII relevant information; 'assessment' refers to judgement, appraisal or evaluation of that information. 
exert steering effects on organisational goals and strategic objectives of local universities.

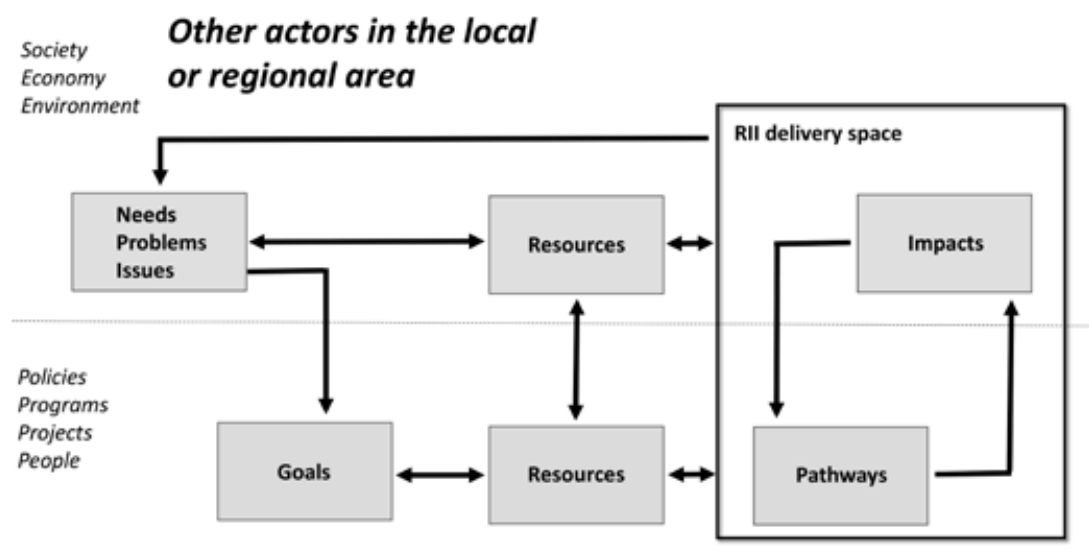

\section{University}

Source: $\quad$ Adapted from Jonkers et al. (2018); European Commission (2004).

Figure 1.1 General descriptive model of a university's RII system

This model describes a meta-level structure of links between different stages in the RII creation process and contributing factors. Acknowledging the fact that many universities tend to be an integral part of their immediate physical environment and spatial territory, we assume that this meta-model will hold, in varying degrees of accuracy, to any kind of university in Europe. The model seems 'closed' in so far as only the university and its local and regional environment interact with each other (involving several entities and at various levels). However, in reality it is merely a niche in a much larger 'open' socio-economic system operating at national or global levels. Figure 3.1 in Chapter 3 presents an enlarged version of the model where the broader geographic setting is incorporated.

The model also introduces the notion of an RII development trajectory; a transactional sequence of successive stages characterised by many 'non-linear' feedback-loops which reflect the complex dynamics of exchanges, interdependencies and interactions between and during the entire process from 'goal to impact'. Clearly, the directionality and intensity of these trajectories are very context- and time-dependent. RII delivery space variables may have non-recursive relationships (bidirectional causality) between parties or partners. This often makes them complex to navigate, which can result in high 
rates of RII failure. The university consists of a 'RII-support architecture' with various facilities and infrastructures that enable RII pathways to generate RII. Depending on the circumstances, there could be very few pathways or many. To mention three such pathways: upgrading an educational curriculum to deliver employable graduates; launching successful start-up companies that create jobs and revenues in the local business sector; engaging in community outreach activities by students or staff that support local innovation-oriented events.

Our RII model also introduces the presence of an abstract 'RII delivery space', which straddles the university and its local environment and is affected by various interrelated resources that feed into it. Owing to non-linear processes and uncertainties in RII development stages this delivery space is characterised by outcome unpredictability. Gradual changes in an RII pathway, such as a new practical module in an entrepreneurship course for students, may lead to a sudden increase of university spin-off enterprises or start-ups. ${ }^{19}$ Similarly, a specific case of successful RII may attract an unexpected flow of external funds that in turn may support existing RII pathways or create new ones. Monitoring the performance of RII pathways may therefore provide a useful indication of development trajectories towards achieving longer-term RII objectives.

Our model is specifically designed for such analytical purposes. However, first we need to be clear about what the various analytical concepts mean. Box 1.1 presents the terminology we apply throughout this book. A university's 'RII profile' is narrowed down to its 'Goals', 'Resources', 'Pathways' and 'Impacts' and is explicitly linked to the broader context of societal needs, problems and issues in the university's city environment or wider region. The presence of RII-relevant infrastructures, facilities, and other resources, comprises what we refer to as 'RII capacity'. Other resources may also contribute to generating regional innovation impacts, notably from external sources and partners in the region. Lacking sufficient empirical information, in many cases it will be unclear to what degree a university's current 'RII profile' can be adequately described and analysed according to the terms 'RII capacity' and 'RII capability'. We then apply a forward-looking perspective and use the general term 'RII potential' to refer to either capability or capacity. Looking backwards, we apply 'RII performance' to describe RII outcomes that directly relate to prior investments or activities of the university.

19 A university 'spin-off' firm is based on, or supported by, university-owned intellectual property; a university 'start-up firm' is founded and/or supported by a university but without IP ownership. 


\section{BOX 1.1 RII ANALYTICS TERMINOLOGY}

Distinguishing the series of closely related general terms, we adopt the following definitions:

- RII profile: summary description of all RII-related information;

- RII portfolio: information on ongoing RII-related investments, activities, projects and programmes;

- RII capability: the ability to initiate or perform actions towards an RII relevant task or goal (an 'RII outcome' in the RII delivery space);

- RII capacity: the volume, size or quantity of resources or assets to pursue an RII outcome;

- RII competence: the state or quality of being functionally adequate to produce RII outcomes at the required or expected level(s) of performance;

- RII potential: having the capability and/or capacity to develop a future RII outcome;

- RII performance: observable and attributable RII outcomes.

\subsection{ORGANISATIONAL DIVERSITY AND REGIONAL DIFFERENTIATION}

Universities can produce significant value, as a primary source of knowledge, skills, and innovation, to their home regions. Most EU regions have at least one university within their territory, but the value depends as much on the university as on its local socio-economic environment. It also depends on how you define or delineate the geographical area (see Box 1.2).

\section{BOX 1.2 DELINEATING A UNIVERSITY'S 'REGION'}

Acknowledging and appreciating RII activities and objectives assumes shared understanding of what that 'region' actually is. Although a university is usually clearly defined and delineated, its region is not necessarily viewed the same by all relevant parties. Universities may see their 'region' as a functional interaction space, a highly dynamic area that is defined by physical proximity but also by changing opportunities. Depending on the circumstances, that flexible and ambiguous viewpoint may comprise of local, metropolitan and urban areas, as well as the surrounding rural area.

In contrast, local, metropolitan or regional authorities are likely to think in terms of a more static 'area of influence' based on a fixed spatial territo- 
ry and associated administrative bodies. Different agencies may also have different definitions and boundaries, creating confusion within government.

Mismatches between the various viewpoints - either 'functional' and 'administrative' - may create misunderstandings between universities and authorities concerning a university's RII activities, goals and performance. RII analysis or assessment should deal with this issue on a case-by-case basis, and avoid implementing a detailed territorial delineation if the broad concept of 'region' serves no analytical purpose.

Universities can contribute to capacity building or expanding the demand side through new business formation, student enterprises, and graduate placements as well as encouraging staff to actively engage with local businesses. Universities can also make important contributions and offer a range of services to other sectors of society, especially health. The presence of a university makes cities and urban agglomerations more attractive places to invest and live. Academic staff and the student base of universities contribute to the overall diversity and vibrancy of the cities in which they are located. This is particularly important as the market for inward investment is becoming increasingly competitive, both in Europe and worldwide. Increasingly, regional governments and local authorities look upon their universities as high-value strategic assets, to be incentivised and exploited for further development of the city or region. A university's regional orientation and outreach activities can be highly organisation-specific and place-specific, depending on its organisational capabilities and strengths as well as obstacles and opportunities in the regional environment (Technopolis et al., 2012). The nature and intensity of a university's contribution is affected by 'scale and scope' effects on both the university's knowledge supply side, but also the regional demand side and how it is articulated (Kempton et al., 2013). In contrast to those universities located in Europe's state capitals or its major cities, universities in provincial capitals or secondary towns are often the largest employer in their urban area.

Universities not only contribute to the attractiveness of a region as a knowledge centre, since their connections with business enterprises and private sector organisations can also help create or support regional innovation systems. The responsiveness and absorptive capacity of the regional socio-economic environment plays an important role in determining the nature and level of those regional interactions and impacts (Edwards et al., 2020). In economically advanced regions, usually with more advanced innovation systems, there are greater prospects for knowledge transfer and exchange activities with R\&D-intensive businesses. Knowledge-intensive business enterprises may significantly benefit from the presence of a critical mass of knowledge-generating universities within close proximity, which can 
provide inputs essential to business sector R\&D-based innovation processes (e.g. Boschma, 2005; Laursen et al., 2011).

Regional engagement and RII potential depend on the breadth and strength of connectedness, but also on framework conditions such as national legislation, regional support and funding systems, physical infrastructures, and the dynamics of the local innovation system. Geographical distance may also play a major role. The geography of innovation in Europe's larger nations is frequently skewed towards large metropolitan areas, or mega cities in some cases, thus introducing significant economies of agglomeration.

It is easier for graduates to find employment in places where government agencies, innovative firms and entrepreneurs tend to agglomerate (Feldman, 2001), in particular the densely populated areas of a capital city. Large universities in metropolitan areas have more options to develop a portfolio of regional activities than small universities in rural areas. Large cities, usually the home base of many universities, also tend to have sizable associated knowledge infrastructures, such as research institutes and science parks, which can ultimately develop into knowledge-intensive economic clusters and innovation hubs.

The further a university is separated from a country's economic or political centre, either the capital city or one of its regional hubs, the lesser the level of regional or national connectivity is likely to be, and the lower the potential for effective knowledge transfer, mobility and economic impact (Brown, 2016). This is particularly critical in the context of developing cities or regions that are struggling to create an innovation-supported development path. In those less advanced regions, which are often less densely populated and predominantly rural, the contribution of universities focuses on its 'human capital development' mission: teaching and training of students. Research activities are of lesser significance, or limited to developing research strengths in niche areas that are particularly relevant for local small or medium-sized employers and perhaps one or two major companies in the regional economy (e.g. Nilsen and Lauvås, 2018).

While a city or urban agglomeration might possess a university, or several universities, with sufficient RII potential there might be limited absorptive capacity within enterprises at close geographic proximity, especially among 'low tech' or services-oriented SMEs with no in-house R\&D. Universities in such regions can contribute to capacity building or expanding the demand side, such as through new business formation, promoting student enterprises and graduate placements, as well as encouraging staff to actively engage with local businesses. Europe's 'regional universities'; those operating almost entirely within sub-national regional contexts, are also more likely to develop productive university-community engagements and responsiveness to needs of municipal or regional stakeholders (Benneworth et al., 2018). Regionalising 
units will be expanding their activities within the local agglomeration - especially in the case of specialised, small universities that are heavily engaged with local partners.

A university's regional impact does not necessarily flow only from an exclusive orientation towards its home city or region. Given the increasingly important policy objective to stimulate inter-regional collaboration, RII analysis should also explicitly consider activities and impacts of universities beyond their immediate surroundings. Increasingly, many graduates and researchers at research-active universities have to be both globally functioning and locally connected. The 'global' research-active universities operating in international markets are less constrained by regional or domestic policies and are likely to continue developing along internationalisation paths. Some internationalising units at universities will step up their operations in the global arena, while remaining strongly rooted in their own national system. By virtue of their size and the centrality of their research and knowledge production roles, global research-active universities operate simultaneously in regional, national, and global environments. Universities with a global reach can be magnets of economic activity in the local environment. The extended geographical impact of universities, either nationally, in other parts of Europe, or even worldwide should be incorporated in contextualised analysis or assessment of their regional engagement and impacts. 